\title{
APLICAÇÃO DE ELETRORRESISTIVIDADE PARA ESTUDOS DE ZONAS DE FRATURA EM ROCHAS CRISTALINAS
}

\author{
Alexandre Bondioli, IAG/USP, Brasil, Vagner Roberto Elis, IAG/USP, Brasil.
}

Copyright 2014, SBGf - Sociedade Brasileira de Geofísica

Este texto foi preparado para a apresentação no VI Simpósio Brasileiro de Geofísica, Porto Alegre, 14 a 16 de outubro de 2014. Seu conteúdo foi revisado pelo Comitê Técnico do VI SimBGt, mas não necessariamente representa a opinião da SBGf ou de seus associados. É proibida a reprodução total ou parcial deste material para propósitos comerciais sem prévia autorização da SBGf.

\section{Resumo}

Com o intuito de desenvolver e testar uma metodologia geofísica adequada para a caracterização (mergulho) de fraturas visando à extração de agua subterrânea, foram feitos modelos de zonas de fraturas nas mais diferentes situações, tendo como base uma rocha cristalina e, a partir destes modelos, fizemos uma analise de resistividade, e para tal foram utilizados programas de modelagem 2D e de inversão de dados 2D.

\section{Introdução}

A geofísica aplicada pode ser definida como a utilização de parâmetros físicos dos materiais terrestres para a procura de objetos geológicos de interesse em subsuperfície, como minérios, petróleo e água, por exemplo. O emprego da geofísica é possível devido as características físicas dos materiais, como densidade, velocidade de propagação de onda, condutividade elétrica, variarem amplamente em função da mineralogia, grau de alteração, grau de umidade, fraturamento, porosidade e outros fatores. Dessa forma, pode-se procurar por determinado material indiretamente, através do conhecimento da resposta de um parâmetro físico para este material.

Esse campo de aplicação das geociências foi desenvolvido, a princípio, para auxiliar a prospecção de minérios. Nos últimos tempos, no entanto, tem experimentado um grande desenvolvimento em estudos hidrogeológicos, ambientais e de engenharia.

Em estudos hidrogeológicos, a aplicação de métodos geofísicos, em especial dos métodos elétricos, tem aumentado em função da crescente demanda de água de boa qualidade. Essa procura por água se dá em função do mau uso dos recursos hídricos, tanto no âmbito do desperdício como também na degradação por processos de poluição ambiental dos mananciais existentes. Dentro desse contexto, a busca de novas metodologias de prospecção de águas subterrâneas também cresce, sendo que os métodos geofísicos têm sido aplicados para auxiliar na resolução dos seguintes problemas, tais como localização de camadas e fraturas, determinação de profundidade, extensão lateral, espessura, volume e nível hidrostático do aquífero, avaliação de porosidade, detecção e monitoramento de aguas subterrâneas entre outras coisas.

Nesse campo das geociências, são amplamente utilizados os métodos elétricos de prospecção geofísica, que se utilizam principalmente da condutividade elétrica e seu inverso, a resistividade, para a investigação dos objetos de interesse.

No entanto, principalmente em regiões onde ocorrem rochas cristalinas, o sucesso na locação de poços, mesmo com a ajuda de metodologia geofísica, tem ficado em níveis ainda insatisfatórios. O meio fraturado é considerado como um domínio hidrogeológico heterogêneo e anisotrópico, onde a presença de água depende da intensidade, abertura e interconexão da rede de fraturas. Esse comportamento é responsável pela dificuldade de locação de poços em zonas cristalinas. Para estudar esse problema, o conhecimento da assinatura geofísica de zonas fraturadas que contém água em boa quantidade e a determinação de sua posição exata e seu mergulho através da utilização de metodologia apropriada são muito importantes. Esse projeto tem como meta colaborar no entendimento das respostas de resistividade elétrica $2 \mathrm{D}$ para zonas de fraturas em áreas de rochas cristalinas.

\section{Metodologia}

O projeto em questão tem como objetivo principal desenvolver e testar uma metodologia geofísica adequada para a caracterização (mergulho) de fraturas visando à extração de agua subterrânea. As ferramentas utilizadas para tal fim foram um software de modelagem 2D de várias situações de um meio cristalino com fratura - variações no mergulho da zona de fratura, espessura e capeamento do solo.

Para que alcançássemos nosso objetivo, primeiramente criamos modelos $2 \mathrm{D}$ como o software de modelagem direta RESIXIP2Di (INTERPEX, 1997) e a partir dele geramos dados de resposta geoelétrica para esses modelos. Após isso, submetemos os dados calculados por esses modelos a um software de inversão de dados, RES2Dinv (LOKE, 2007), que resultaram em seções de resistividade para as situações que modelamos.

Foram criados seis modelos diferentes com fraturas, desde o mais simples, até o mais próximo ao caso real, e mais dois modelos sem fraturas, para que possamos usá-lo como base de comparações. Para todos os modelos, estamos trabalhando com uma fratura de resistividade de 100 ohm.m em uma rocha com resistividade de 1000 ohm.m. 

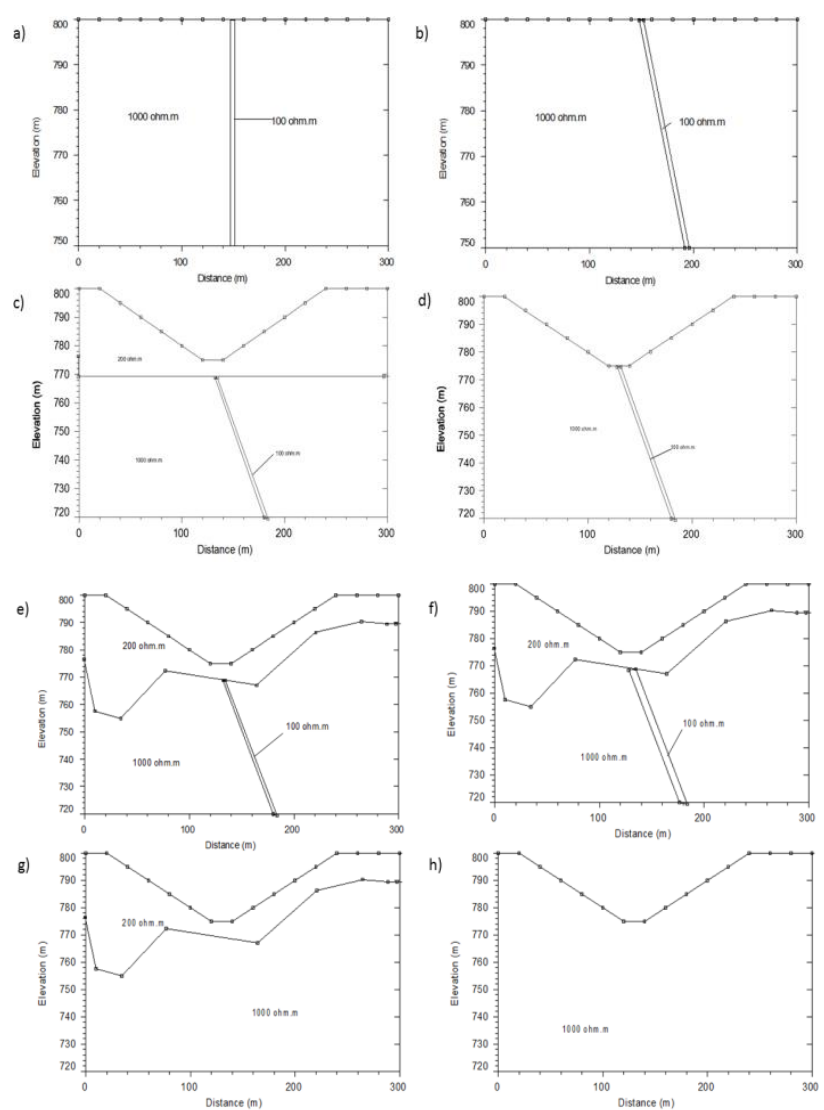

Figura 1: a) modelo 1. b) modelo 2. c) modelo 3. d) modelo 4. e) modelo 5. f) modelo 6. g) modelo sem fratura, mas com a camada de solo. h) modelo sem solo, mas com topografia.

No modelo 1 , temos apenas a rocha com uma fratura vertical, com mergulho $90^{\circ}$ sem variação de topografia. No modelo 2, temos a fratura ocorrendo com um mergulho desconhecido, mas ainda sem variação de topografia. No modelo 3, conservamos a fratura com o mergulho desconhecido e acrescentamos uma variação de topografia. No modelo 4 , acrescentamos uma camada reta de solo, de resistividade 200 ohm.m mantendo o resto igual aos anteriores. No modelo 5 , a camada de solo não possui mais o contato com a rocha plano, ocasionando que tanto a espessura da camada de solo quanto a da rocha variem. No modelo 6 , mantivemos a mesma situação do modelo 5 , mas dobramos a largura da zona de fraturas. Por fim, no primeiro modelo sem fraturas, encontra-se a rocha com resistividade 1000 ohm.m e com a topografia e no segundo encontra-se a rocha com uma camada de solo de espessura variável, para comprarmos com o caso 5 e 6 .

\section{Resultados}

A partir dos modelos feitos, usamos o software RES2Dinv para gerar perfis de resistividade para cada modelo, a fim de que pudéssemos entender como ficaria a resposta de cada modelo.

$\mathrm{Na}$ figura 2 vemos os perfis de resistividade dos modelos 1 e 2 , os quais não possuem topografia.
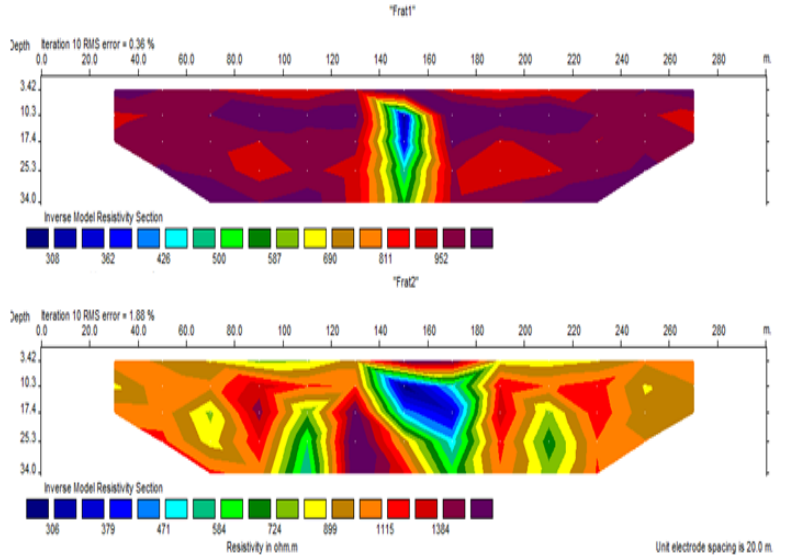

Figura 2: perfis de resistividade dos modelos 1 e 2, que não possuem topografia.

Podemos ver que no caso do modelo 1, fica bem nítido onde está a zona de fraturas, já que estamos falando de uma zona de fraturas perpendicular a superfície. No segundo modelo, ainda podemos identificar a zona de fraturas, mas agora não mais com tanta facilidade como no primeiro modelo, mostrando que um possível mergulho da zona de fraturas poderia dificultar.

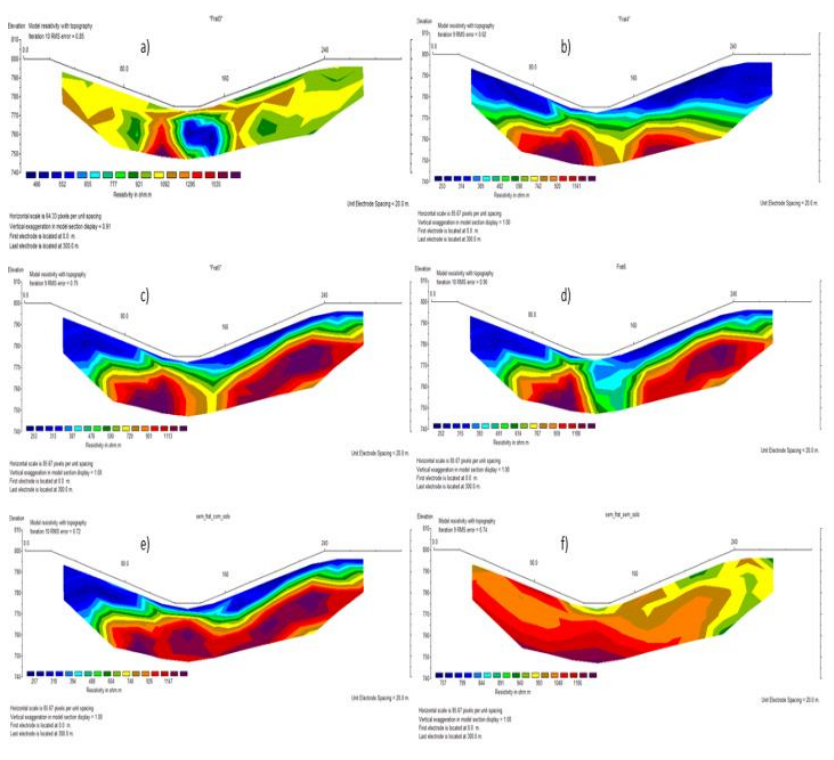

Figura 3: a) perfis de resistividade dos modelos como topografia, b) e com uma camada de solo com limite inferior constante, c) com limite variando, d) com a zona de fratura mais estreita. e) Perfis de resistividade dos modelos sem a fratura mas com solo e f) do modelo sem fratura e sem camada de solo.

$\mathrm{Na}$ figura 3, temos os perfis de resistividade dos modelos com topografia e dos modelos para comparação, sem zona de fraturas. Podemos observar que no modelo com a zona de fraturas mais estreita (3d) a zona de fratura quase não aparece, olhando simplesmente para a figura, mas ao comparar com o modelo sem fraturas (3e) conseguimos identifica-la e localiza-la. 


\section{Discussão e Conclusões}

Os resultados das modelagens mostram que modelos simples com bons contrastes de resistividade possibilitam a identificação clara da zona de fratura. Modelos mais complexos, com topografia não plana e camada de solo de espessura variável podem tornar difícil a identificação de zonas de fratura pouco espessas. O efeito de isolado um baixo topográfico, que é o mais comum em zonas de fratura, resulta em uma zona mais resistiva. Dessa forma, em estudos de campo, se houver anomalia de baixa resistividade em locais de baixo topográfico, isso deve ser causado por uma zona de fratura, como foi observado nos resultados obtidos dos modelos.

\section{Agradecimentos}

Os autores agradecem o Departamento de Geofísica do IAG pela estrutura oferecida para o desenvolvimento do trabalho e ao CNPq pela bolsa de Iniciação Científica.

\section{Referências}

INTERPEX LIMITED - 1996 - RESIX IP2DI v3 Resistivity and Induced Polarization Data Interpretation Software. User's Manual. INTERPEX Limited, Golden, Colorado, U.S.A., 280 p.

LOKE, M.H. [2007] RES2DINV ver. 3.4 - 2D resistivity and IP inversion. Penang: M.H. Loke Software User's Manual. 